\title{
Factors influencing social involvement and vocational activities in patients with traumatic spinal cord injury
}

\begin{abstract}
Traumatic spinal cord injury (TSCI) adversely affects person's functioning and wellbeing. TSCI mostly occurs in adults of working age and inhibits their career development. Determination of factors influencing social and vocational status of patients with TSCI is crucial in order to address the problem more purposefully.
\end{abstract}

Keywords: traumatic spinal cord injury, social and vocational rehabilitation
Volume 2 Issue 4 - 2017

\author{
Elena Vasilchenko,' Alexander Kulikov, ${ }^{2}$ \\ Marina Zhestikova, ${ }^{3}$ Karine Karapetian ${ }^{4}$ \\ 'Department of Medical Rehabilitation, Ministry of Labour and \\ Social Protection of the Russian Federation, Russia \\ ${ }^{2}$ Department of Physical Therapy, Ministry of Healthcare of the \\ Russian Federation, Russia \\ ${ }^{3}$ Department of Medical Rehabilitation, Ministry of Healthcare \\ of the Russian Federation, Russia \\ ${ }^{4}$ Department of Information and Analysis, Ministry of Labour \\ and Social Protection of the Russian Federation, Russia
}

\begin{abstract}
Correspondence: Elena Vasilchenko, Associate Professor, Acting Director General, Federal State Budgetary Scientific and Practical Centre for Medical and Social Evaluation and Rehabilitation of Disabled Persons in Novokuznetsk, Ministry of Labour and Social Protection of the Russian Federation, Russia, Tel (3843) 37-82-94, Fax (3843) 37-59-08,

Email root@reabil-nk.ru
\end{abstract}

Received: November 28, 2017 | Published: December 14, 2017
Abbreviations: TSCI, traumatic spinal cord injury; AIS, american spinal injury association impairment scale; WORQ, work rehabilitation questionnaire; ICF, international classification of functioning disability and health

\section{Introduction}

Traumatic spinal cord injury (TSCI) affects person's quality of life and vocational ties. TSCI remains one of the most devastating health injuries often producing permanent disability. Despite the severity of TSCI consequences the evidence on work activities and vocational status of this category of disabled persons in Russia remains scarcely investigated. Rarely available data show that more than $70 \%$ of TSCI patients are of working age ${ }^{1}$ meaning that matter of work in this population is a vital issue. Numerous studies worldwide show there is a correlation between unemployment and suicide ${ }^{2-4}$ and longer duration of unemployment is related to a greater risk of suicide and suicide attempt. ${ }^{5}$ We believe it is important to determine factors influencing social involvement and vocational activities of patients with TSCI to address the problem in a more comprehensive way.

\section{Materials and methods}

The study includes 71 cases of patients with TSCI who were admitted to the Department of Neurosurgery of the Centre to undergo course of treatment and rehabilitation. Data collection was performed using the Work Rehabilitation Questionnaire (WORQ) a generic instrument that is used to assess and evaluate functioning in patients of different populations in vocational rehabilitation settings. ${ }^{6}$ WORQ is based on the ICF core set for Vocational Rehabilitation.
WORQ consists of 2parts: Partl comprises questions regarding socio demographics and background information; Part 2 consists of series of questions about persons functioning. To fill in Part 2 of the questionnaire patient is asked to assess the degree of problems they experience with each point from 0 -no problem and 10-complete problem. The degree of impairment of the spinal cord conduction was assessed by American Spinal Injury Association Impairment Scale (AIS) ${ }^{8}$ using following categories:

i. $A=$ Complete: No sensory or motor function is preserved in sacral segments $\mathrm{S} 4-\mathrm{S} 5$

ii. $\mathrm{B}=$ Incomplete: Sensory, but not motor, function is preserved below the neurologic level and extends through sacral segments S4-S5

iii. $\mathrm{C}=$ Incomplete: Motor function is preserved below the neurologic level, and most key muscles below the neurologic level have a muscle grade of less than 3

iv. $\mathrm{D}=$ =ncomplete: Motor function is preserved below the neurologic level, and most key muscles below the neurologic level have a muscle grade that is greater than or equal to 3

v. $E=$ Normal: Sensory and motor functions are normal

Severity of disability was determined in accordance with the Russian Federation classification of disability. If p-value was less than 0.05 , the differences were considered as statistically significant. Inclusion criterion was the presence of traumatic spinal cord injury. Exclusion criteria were presence of mental disorders, critical condition and patient's unwillingness to participate in the study. Study was 
approved by Ethics Committee of the Scientific and Practical Centre for Medical and Social Evaluation and Rehabilitation of Disabled Persons in Novokuznetsk. Written informed consent was obtained from all participants.

\section{Results}

Seventy-one patients with TSCI participated in current study: $57(80.3 \%)$ were male, $14(19.7 \%)$ were female. Mean age of all participants was $40.1 \pm 1.3$ years. Mean time duration after injury was $7.4 \pm 0.8$ years. Sixty-two participants $(87.3 \%)$ had the most severe disability group - disability group I; 3 patients $(4.3 \%)$ had disability group II; 2 patients (1.8\%) had disability group III; and 4 patients(3.6\%) had no disability group. Eighteen(25.4\%) had AIS A; 24 patients(33.8\%) had AIS B; 16 patients(22.5\%) had AIS C;13 patients(18.3\%) had AIS D; no patient had AIS E.

In current study the vocational status of participants was the objective criterion of social and vocational integration. Hence, out of $71(100 \%)$ participants, $3(4.2 \%)$ didn't work because they were studying in either college or university, and 9 participants $(12.7 \%)$ had active working status:

i. $8(12.7 \%)$ were male, $1(1.4 \%)$ was female;

ii. $2(2.8 \%)$ of them had AIS A, $2(2.8 \%)$ had AIS B, $2(2.8 \%)$ had AIS C, and 3(4.2\%) had AIS D;

iii. $3(4.2 \%)$ were employed ( 1 of them worked full-time; 2 worked part-time); $6(8.4 \%$ ) were self-employed (1 of them worked full-time; 5 worked on modified or light duty)

The overwhelming majority of patients $(n=59,83.1 \%)$ were neither working nor involved in any kind of vocational or educational retraining. Preliminary analysis revealed that social involvement and vocational activities were not associated with such variables as level of injury, severity of neurologic deficit (AIS type), time duration after injury age of gender. Statistically significant correlations were found in following items: problems with usual daily activities because of feeling worried or anxious $(\mathrm{r}=0,325, \mathrm{p}=0,006)$; general endurance when performing physical activities $(\mathrm{r}=0,328, \mathrm{p}=0,005)$; lifting and carrying objects weighing up to $5 \mathrm{~kg}(\mathrm{r}=0,300, \mathrm{p}=0,011)$; lifting and carrying objects weighing more than $5 \mathrm{~kg}(\mathrm{r}=0,253, \mathrm{p}=0,033)$; fine hand use $(\mathrm{r}=0,330, \mathrm{p}=0,005)$; moving around $(\mathrm{r}=0,334, \mathrm{p}=0,005)$; dressing $(\mathrm{r}=0,252, \mathrm{p}=0,034)$.

\section{Conclusion}

Findings show that employment isn't associated with either level of injury or severity of neurologic deficit, and is mostly associated with ICF categories of Mobility domain. These findings allow us to set the rehabilitation goals and tasks more results-oriented. Based on that we can presume this population of patients has a potential to become more independent.

\section{Acknowledgements}

None.

\section{Conflict of interest}

The authors have no conflict of interest.

\section{Refererences}

1. MA Leontyev, OD Ovchinnikov. The study of the indications for recovery of locomotor functions in patients with TSCI and factors impeding locomotion. Bull Kuzb Sci Cen SB RAMS. 2005;1:131-136.

2. Jin RL, Shah CP, Svoboda TJ. The impact of unemployment on health: a review of the evidence. CMAJ. 1995;153(5):529-540.

3. Platt S. Unemployment and suicidal behaviour: a review of the literature, Soc Sci Med. 1984;19(2):93-115.

4. Wilson SH, Walker GM. Unemployment and health: a review. Public Health. 1984;107(3):153-162.

5. Milner A, Page A, La Montagne AD. Long-Term Unemployment and Suicide: A Systematic Review and Meta-Analysis. PLOS One. 2013;8:e51333

6. http://myworq.org/questionnaire_ru.php

7. https://www.icf-research-branch.org/icf-core-sets-projects2/diversesituations/icf-core-sets-for-vocational-rehabilitation

8. Kirshblum SC, Waring W, Biering SF, et al. Reference for the 2011 revision of the international standards for neurological classification of spinal cord injury. J. Spinal. Cord Med. 2011;34(6):547-554. 